\title{
Determinants and Prevalence of Rural Poverty in West, East and Southern African Countries
}

\author{
Joachim Nyemeck Binam ${ }^{1 *}$, Judith Oduol ${ }^{2}$, Luke Olarinde ${ }^{1}$, Aliou Diagne ${ }^{3}$, Adewale Adekunle ${ }^{4}$ \\ ${ }^{1}$ Forum for Agricultural Research in Africa (FARA) Sub-Saharan Africa Challenge Program (SSA CP) KKM \\ PLS-IAR-Agric Research Station (ARS), Kano, Nigeria \\ ${ }^{2}$ Forum for Agricultural Research in Africa (FARA), Kachwekano Zonal Agricultural Research and \\ Development Institute, Kabale, Uganda \\ ${ }^{3}$ Africa Rice Center (AfricaRice), Cotonou, Benin \\ ${ }^{4}$ Cantonments, Forum for Agricultural Research in Africa (FARA), Accra, Ghana \\ E-mail:jbinam@fara-africa.org,nyemeckbijoa@yahoo.fr. \\ Received February 09, 2011; revised April 3, 2011; accepted April 15, 2011
}

\begin{abstract}
In this paper, we determine the extent to which the variation in poverty incidence can be explained by institutional/community factors, and how the results can be used to evaluate the potential impact on poverty levels of change in factors found to have a significant influence on poverty incidence in some selected countries of East, Southern and West Africa. At the country level, the set of important variables is diverse and includes access to infrastructure (institutional dummy variables), and village resources endowment (community-based variables). The findings derived from this paper suggest that more than four-fifths of households in the study area need to be escaped from poverty. We also found that the poverty rate could be lowered by $17 \%$ to $89 \%$ in the involved countries through investment/actions leading to access to input and output markets, awareness and adoption of improved crop varieties and best-bet practices, better access to rural credit and capacity building of community-based organizations. This indicates that these variables can have powerful effects in terms of long-term poverty reduction strategies.
\end{abstract}

Keywords: Africa, Innovation Platform, Logit, MCA, Poverty, Welfare Index

\section{Introduction}

Halving world extreme poverty between 1990 and 2015 is the first Millennium Development Goal. With rural poverty accounting for some $75 \%$ of world poverty, meeting this goal requires reducing poverty in rural areas. Well-known scholars, politicians, foundations and academic groups have highlighted poverty in Africa as a priority development challenge and have dedicated considerable effort and resources toward its alleviation [1-4]. Despite this widespread attention, confusion still exists over the language and evidence used to identify poverty in Africa and this is especially true for the Sub-Saharan Africa [4].

According to [5], the burden of poverty is spread evenly among regions of the developing world, among countries within those regions and among localities within those countries. In the rural areas large differences in income and consumption exist not only along racial lines but amongst Africans between regions and within specific communities.

Evidence from poverty maps for Africa and other developing countries shows that poverty and income distribution are not homogenous and vary widely across space. Some of these differences are caused by differences in geographic and agro-climatic conditions, infrastructural access to market and public facilities, the presence and absence of natural resources such as forest and water bodies etc. [6,7]. Poverty in rural areas was associated with the crisis in the agricultural sector due to intermittent rainy seasons, persistent droughts, lack of draught power and lack of proper agricultural technology [8].

Even though these factors have been identified as major contributors to differences in the standards of living of populations in different areas, there has been little empirical work to ascertain the exact relationship between welfare level and these factors. 
This study examines the determinants of poverty prevalence for households, defined in rural locations of countries within the Sub-Saharan Africa Challenge Programme (SSA-CP).

The key research questions in this study are: i) what is the poverty prevalence across rural households in the country within the Sub-Saharan Africa challenge programme? ii) what factors account for the variation in community-level poverty across rural households? iii) does the relationship between household-specific, community and institutional variables differ significantly among countries? iv) what are the potential poverty impacts of investment/changes in some of the institutional or community related factors found to influence poverty in different countries within the SSA CP?

The paper is organized as follows: the second section presents the theoretical framework and the estimation techniques within the third section we describe the sampling method and data. The fourth section contains the estimation results and discussion, with conclusion being presented in the fifth section.

\section{Theoretical Framework and Estimation Techniques}

\subsection{Defining and Measuring Poverty in the West, Central and East Africa}

According to Chambers [9], a household is characterized as poor when it has few assets, its hut, house or shelter is small and made of wood, bamboo, mud, grass, reeds, palm fronds or hides, its meager furnishings include only mats or hides for sleeping and perhaps a bed, cooking pots and a few tools, and there is no toilet. The household has no land or has land that does not assure or barely assures subsistence. It has no livestock or has only small stock (hens, ducks, goats, a pig, etc.). The household's stocks and flow of food and cash are low, unreliable, seasonal and inadequate. It is either locked into dependence on one patron for whom most work is done or continues a livelihood with a range of activities that reflect tenacious ingenuity in the face of narrow margins for survival. Returns to the family labour are low and in the slack seasons often very low if indeed there is any work at all. Poor households tend to have few buffers against contingencies; small needs are met by drawing on slender reserves of cash, by reduced consumption, by barter, or by loans from friends and relatives. These situations make the household so vulnerable that the family is especially prone to sickness and death. Chambers also uses the concept of the deprivation trap to explain poverty as a vicious circle. It is also argued that the isolation factor (lack of education, remoteness, being out of contact) sustains poverty. Services cannot reach those who are remote, and illiterates cannot read information of economic value and have difficulty obtaining loans. Evidence by [10] in their Mauritania poverty study also suggests that the isolation factor is critical in poverty issues.

As noted by [11], poverty measurement involves three steps: choosing a quantitative welfare indicator, choosing a means of discriminating between the poor and nonpoor (through the use of a poverty line), and aggregating this information into a poverty measure for a particular population. Household-level analysis will be undertaken because, as noted by [10] and [11], poverty is fundamentally a household-level phenomenon and this is the level at which some micro data are available.

There are different approaches to the measurement of poverty and inequality. In essence, one can distinguish between the conventional approach to the measurement of poverty and inequality, which is money-metric and uses income and/or expenditure data, and a number of alternative approaches such as those that employ various other socioeconomic indicators to measure poverty and inequality. Of these alternatives or the so-called multidimensional approaches to the measurement of poverty, the welfare composite index (WCI) approach applied to data from Demographic and Health Surveys (DHS) has gained increasing popularity in recent years $[12,13,5]$.

In the money-metric approach the poverty analysis requires the definition of poverty line below which an individual is considered as poor. Studies based on monetary welfare indicators (income or expenditure) are often characterized by different points of view concerning the choice of the poverty line [14]: an "absolute" poverty line is set so as to maintain a constant purchasing power across countries/communities, whereas a "relative" poverty line is allowed to vary with a country's/community's average income. A common practice is to set the standard poverty line of USD 1.25 per equivalent adult adjusted with the local purchasing power parity (PPP) exchange rate. For the purpose at hand, it is the absolute approach that is relevant for our analysis.

In the non-monetary framework the choice of the poverty line is somewhat less debatable for at least two reasons: the definition of the absolute poverty line is not obvious since the WCI used does not include the nutritional dimension which is helpful in determining a minimum subsistence threshold. Secondly, there is a need to determine a set of welfare indicators deemed essential for every individual to achieve a minimum level of well-being. The choice of such indicators could be arbitrary given the poor knowledge of this rural area lifestyle. To give some robustness to our analysis, we are going to define two relative poverty lines: a lower line, which corresponds to the $25^{\text {th }}$ percentile of the distribu- 
tion, and an upper line corresponding to the $40^{\text {th }}$ percentile of the same distribution [13].

The aim of this paper is to analyze trends in poverty and their determinants in different countries within the Sub-Saharan Africa Challenge programme. One can argue that this paper is not unique, given that various estimates of the extent of poverty and inequality in these African countries have in fact been published. In the past decade, moreover, there has been a considerable expansion of our knowledge of poverty (and inequality) in Africa, following the increased availability of representative survey data on income and/or expenditure for a growing number of African countries. Our effort, however, differs from these previous studies in three important respects. Firstly, and most importantly, we use both money-metric and multidimensional approaches to assess the poverty status of households and their determinants. Secondly, in our multidimensional poverty measure approach, we employ multiple correspondence analysis (MCA) rather than principal components analysis (PCA) to construct the asset index. This methodology is more appropriate as MCA was designed for the analysis of categorical variables and, unlike PCA, which is appropriate for multivariate analysis of continuous variables, does not presume that indicator values are normally distributed [15-17]. Thirdly, our analysis that uses baseline data from within the Sub-Saharan Africa Challenge programme is not only confined to poverty alone, as do the majority of authors who have published in this field, but also analyzes their determinants.

\subsubsection{The Welfare Composite Index}

A prerequisite of our empirical analysis is a clear definition of what we mean by household welfare indicator. Unlike the widely used procedures that proxy households' wealth by income or expenditure, we generate an index of household ownership and housing characteristics, referred to as welfare composite index (WCI) as another proxy for household wealth.

Let us briefly present the outline of general methodology followed in constructing the WCI. A more detailed presentation can be found in [18].

Let us consider $K$ primary indicators which reflect household living conditions, such as the ownership of some agricultural and non-agricultural goods and household conditions. The basic idea is to summarize the information provided by these qualitative indicators on a single composite index, $A$, which can be written by a household $i$ by:

$$
A_{i}=\sum_{j=1}^{K} \gamma_{j} I_{i, j}
$$

where $I_{i, j}$ is a primary indicator $j(j=1 \cdots K)$ for household $i(i=1 \cdots n)$ and $\gamma_{j}$ is the weight of the indicator $I_{i, j}$, to be estimated.

Many different methods have been used to estimate $\gamma_{j}$ $[13,12,19]$. In this study we used the multiple correspondence analysis (MCA) suggested by [19]. This method is particularly suitable for the data available for this study which include a set of binary variables representing the different modalities taken by our primary indicators [17].

Each primary indicator $I_{i, j}$ can take $J$ modalities, thus $A_{i}$ the composite index for household $i$ can be rewritten as:

$$
A_{i}=\frac{\sum_{k=1}^{K} \sum_{j k=1}^{J K} w_{j k}^{k} I_{i j k}^{k}}{K}
$$

where $K$ is the number of primary indicators;

$J_{k}$ is the number of indicators $k$ modalities;

$w_{j k}^{k}$ is the weight attributed to $J_{k}$ modalities; and

$I_{i j k}^{k}$ is a binary variable equal to 1 when household $i$ has modality $J_{k}$, and 0 otherwise;

The WCI, $A_{i}$ for a household $i$, is simply the average of the weight of the binary variables the weight to attribute to each composite index, $A_{i}$ is the normalized score

$$
\frac{w_{j k}^{k}}{\gamma_{\alpha}}=\frac{\text { score }}{\text { eigen value for axis } a} \text { of the modality } I_{i j k}^{k} \text { b- }
$$
tained from the MCA.

\subsubsection{Foster, Greer and Thorbecke (FGT) Poverty Measure}

Several poverty index measures are proposed in the poverty literature. In this paper we use the family of the poverty measures proposed by [20], which satisfy several desirable properties, especially decomposition by subgroups. FGT measures are defined by:

$$
F G T_{\alpha}=\frac{1}{n} \sum_{j=1}^{K} I_{y}\left(z-y_{i}\right)^{\alpha}
$$

where $I_{y}$ is an indicator function equal to 1 if $y_{i} \leq z \quad 0$ otherwise $y_{i}$, is an individual $i$ 's welfare indicator (WCI) or the income per capita, $z$ is the poverty line, $n$ is the size of the population, and $\alpha$ a non-negative parameter. For $\alpha=$ $0, F G T_{0}$ simply represents the proportion of the poor, referred to as headcount (HC) or poverty incidence (PI). For $\alpha=1, F G T_{1}$ represents the average poverty gap, and expresses WCI or the level of income necessary for an individual to be able to reach the poverty threshold. When $\alpha=2$, the index also reflects the distribution of poverty amongst the poor and places greater weight on those furthest from the poverty line. This is referred to as poverty severity or the squared poverty gap index. It is sensitive to inequality amongst the poor, since a higher weight is placed on those who are farthest away from the 
poverty line [11]. For all of the measures, the higher the $P$ is, the higher is the poverty level.

\subsubsection{Poverty Decomposition}

The $\mathrm{FGT}_{\alpha}$ indices satisfy the property of decomposability by sub-group. In other words, the overall poverty index can be expressed as a weighted sum of poverty level within each sub-group. Let us consider the partition of the whole population in $\mathrm{K}$ exclusive sub-groups, with $\phi(k)$ the relative size of each sub-group $k$. The $F G T_{\alpha}$ can be expressed as:

$$
F G T_{\alpha}=\frac{1}{n} \sum_{i=1}^{K} \phi(k) F G T_{\alpha}(z, k)
$$

where $F G T_{\alpha}(z, k)$ denotes the poverty index of the sub-group $k$. Ceteris paribus, the improvement in the well-being of a given sub-group implies the improvement of the well-being in the entire population. Such decomposition has the advantage that it can permit the decentralization of the targeting programme in each sub-group. In the following sections we present the FGT index for $\alpha$ or 1 by localities and different household characteristics (Social capital, access to input market, access to output market, and use of improved varieties....).

\subsection{Identifying the Main Determinants of Poverty}

The approach we follow intends to explain why some population groups are non-poor or poor. In the first stage, we identify the poor and non-poor using the FGT poverty measures as described in the previous sub-section, whereas in the second stage, we examine the probability of being poor. We assumed that the probability of being in a particular poverty category is determined by an underlying response variable that captures the true economic status of an individual. In the case of binary poverty status (i.e. being poor or non-poor), let the underlying response variable $y^{*}$ be defined by the regression relationship:

$$
y^{*}=\sum x_{i}^{\prime} \beta+u_{i}
$$

where $\beta^{\prime}=\left[\beta_{1}, \beta_{2}, \cdots, \beta_{k}\right]$ and $x_{i}^{\prime}=\left[1, x_{i 1}, x_{i 2}, \cdots, x_{i k}\right]$

In Equation (5), $y^{*}$ is not observable, as it is a latent variable. What is observable is an event represented by a dummy variable $y$ defined by:

$$
\begin{aligned}
& y=1 \text { if } y^{*}>0, \text { and } \\
& y=0 \text { otherwise }
\end{aligned}
$$

From Equation (5) and (6) we can derive the following expression:

$$
\begin{aligned}
\operatorname{Prob}\left(y_{i}=1\right) & =\operatorname{Prob}\left(u_{i}>-\sum x_{i}^{\prime} \beta_{i}\right) \\
& =1-F\left(-\sum x_{i}^{\prime} \beta_{i}\right)
\end{aligned}
$$

where $F$ is the cumulative distribution function for $u_{i}$, and $\operatorname{Prob}\left(y_{i}=0 \mid \beta, x_{i}\right)=F\left(-\sum x^{\prime} \beta_{i}\right)$

The observed values of $y$ are the realization of the binomial with probabilities given by Equation (7), which varies with $x_{i}$ Thus, the likelihood function can be given by:

$$
L=\prod_{y_{i}=0}\left[F\left(-\sum x_{i}^{\prime} \beta_{i}\right)\right] \prod_{y_{i}=1}\left[1-F\left(-\sum x_{i}^{\prime} \beta_{i}\right)\right]
$$

which can be written as:

$$
L=\prod_{y_{i}=1}\left[F\left(-\sum x_{i}^{\prime} \beta_{i}\right)\right]^{1-y_{i}}\left[1-F\left(-\sum x_{i}^{\prime} \beta_{i}\right)\right]^{y_{i}}
$$

The functional form imposed on $\mathrm{F}$ in Equation (8) ${ }^{1}$ depends on the assumption made about $u_{i}$ in Equation $(5)^{2}$. The cumulative normal and logistic distributions are very close to each other. Thus, using one or the other will basically lead to the same result [21]. Moreover, following [22], it is possible to derive the would-be estimates of a probit model once we have parameters derived from the logit model. Thus, the logit model is used in this paper.

We specified the logit model by assuming a logistic cumulative distribution of $u_{i}$ in $\mathrm{F}$ (in Equation 8.1 and 8.2). The relevant logistic expressions are:

$$
\begin{gathered}
1-F\left(-\sum x_{i}^{\prime} \beta_{i}\right)=\frac{e^{\sum x_{i}^{\prime} \beta}}{1+e^{\sum x_{i}^{\prime} \beta}} \\
F\left(-\sum x_{i}^{\prime} \beta_{i}\right)=\frac{e^{-\sum x_{i}^{\prime} \beta}}{1+e^{-\sum x_{i}^{\prime} \beta}}=\frac{1}{1+e^{\sum x_{i}^{\prime} \beta}}
\end{gathered}
$$

As before, $x_{i}$ is the characteristics of the households/individuals, communities, and $\beta_{i}$ the coefficients for the respective variables in the logit regression. Having estimated Equation (8) with maximum likelihood (ML) technique, Equation (9.1) basically gives us the probability of being poor $\left[\operatorname{Prob}\left(y_{i}=1\right)\right]$ and Equation (9.2) the probability of being non-poor $\left[\operatorname{Prob}\left(y_{i}=0\right)\right]$.

\subsubsection{Description of the Determinants of Poverty}

Based on the above model, we argue in this paper that village; community and household characteristics cause poverty and influence the capacity to escape poverty.

\section{Household composition}

* Age of household head ( $L O G A G E$ ): the poverty profile found little correlation between the age of the household head and poverty. In theory, households with a younger head are less likely to be prosperous than those with a working older one. Households with either older or younger household heads may be more likely to consume less than those with heads of household who are of working age $([23,24])$.

\footnotetext{
${ }^{1}$ The log likelihood function for Equations (8.1) and (8.2) can be written as,

$l(\beta)=\log L(\beta)=\sum_{i=0}^{K} y_{i} \log \left(1-F\left(-\sum x_{i}^{\prime} \beta_{i}\right)\right)+\left(1-y_{i}\right) \log F\left(-\sum x_{i}^{\prime} \beta_{i}\right)$

${ }^{2}$ This basically forms the distinction between logit and probit models.
} 
*Household size (LOG HHSIZE2): the majority of studies have found that a larger household size is correlated with increased poverty. It has been found in Sierra Leone that, poorer households tend to be slighted larger than non-poor households [24,25] highlight the need to examine this issue more thoroughly. [26,27], and [28] used the square of household size as an explanatory variable to allow for non-linearity in the relationship between household size and living standards. Other things being equal, we expect smaller households to be less poor and, following other research, the square of household size is included as an independent variable. In addition, households with a higher share of children are likely to have fewer income-generating opportunities than those with more adults of working age. The regressions include variables for the proportion of children below the age of 16 in the household (CHILDRAT) and that of adults between the ages of 16 and 59 (ADULTRAT).

*Education: the poverty profile showed many correlations between education levels and poverty. In examining Côte d'Ivoire, [28] found household education levels to be a key determinant of poverty in urban, but not in rural areas. [27] found that education, specifically women's education, was a key determinant of household poverty status. Similarly, [26] (2003) found that higher levels of education in Malawi resulted in welfare improvements. [29], on the other hand, using a different data set for Mozambique, found that education was not a significant factor in poverty levels, especially for rural households. The education variables used in this analysis included the level of education of the household head (POSTSEC and POSTPEDU being a dummy variables = 1 if the household head attained post secondary or post primary education respectively and 0 otherwise).

*Social capital: [30] found that higher levels of social capital, as measured by involvement in associations to reflect social norms and relationships in a community, result in higher levels of welfare. [29] also found this to be the case in Mozambique. To capture possible effects of community involvement, a dummy variable for whether or not someone in the household participates in community programmes is included. These variables are specified as:

- MEMBERSHIP (a dummy $=1$ if the household head or any other member belong to a community group);

- EXPEXTN (a dummy variable $=1$ if the household had contact with agricultural extension agents and 0 otherwise)

- RESEARCH (a dummy variable $=1$ indicating if the household participated in the community research demonstrations and 0 otherwise)

*Remittances: This is the only variable for income source used, but if it can be considered an extra source of income, it is likely to improve household welfare. The variable is a simple dummy variable for whether or not the household receives remittances.

Access to infrastructure: Given that poverty was significantly higher in rural areas, access to infrastructure has also been found to be a significant variable in a number of other studies. [28] found that, in rural areas, infrastructure has substantial predictive power: households located in villages that are nearer to paved roads and public markets are better-off. A series of dummy variables have been included in the model to pick up localized effects. These are:

*Variables related to input and output market access including:

- -Variable RESPOND1 being a dummy variable that indicates if there is any market within the community/village;

- -Variable RESPOND3 a dummy indicating if there is any trader or processor being linked with the community/village and;

- - RESPOND6 a dummy variable indicating if there is any agro-dealer shop within the community/village.

*Variables related to the village resources describing the possession of some physical amenities in the community/village. These are dummy variables defined to be equal to one each if the village/community is endowed with the following: schools (POSSES1), hospital, clinic or other health center (POSSES2), worship places (POSSES3), social halls or centers (POSSES4), boreholes or wells (POSSES5), cattle dips, veterinary centers (POS$S E S 6)$, radio-reception channels (POSSES9), all weather roads (POSSES11), livestock watering points (POS$S E S 14)$, rural micro-finance bank (POSSES16), government extension agriculture/livestock office (POSSES17) and, agricultural research site (POSSES18).

\section{Data}

The data used are based on the 2008 baseline survey carried out within the Sub-Saharan Africa Challenge programme's pilot learning sites (SSA-CP PLSs). These data were collected for the seven countries and covered nearly five thousand households. The fundamental rationale behind the choice of a household as a unit of analysis is the assumption of sharing of resources among households.

The data gathered as part of the Kano, Katsina, Maradi, Lake Kivu and Zimbabwe, Malawi and Mozambique pilot learning site (KKM, LK and ZMM PLSs) of the SSA CP provide rich information at the individual/farmer, the household, the village and the community level. The data include information on the awareness and 
adoption of improved crop varieties, food production, access to inputs, capital assets, social capital, household/farmer characteristics, market and marketing, household income and expenditure, food security/insecurity, dietary, credit, agricultural practices and knowledge, amongst others. Table 1 below provides the distribution of households by country, sub-countries and villages, while Table 2 gives the descriptive statistics of variables used to identify the determinants of poverty.

As shown in Table 2, the number of households with members belonging to a farmer group or organization varies from $10 \%$ to $51 \%$ with the maximum number appearing in Uganda (51\%). Throughout the countries, on average, less than $20 \%$ of the households have had contact with agricultural extension agents or participated in community research demonstrations. Moreover, very few communities in these countries possess cattle dips, veterinary centers, all weather roads livestock watering points, rural micro-finance bank, government extension agriculture/livestock office and, agricultural research site.

To construct the wealth index, we select fourteen primary indicators that can be classified into three categories: possession of agricultural equipment, ownership of durable goods and housing conditions. Table 3 presents a detailed description of these indicators. [19] describes the calculation of a composite poverty indicator using MCA as a four-stage process. Firstly, one constructs an indicator matrix (of ones and zeros) that shows the asset ownership of each household. If the households are displayed as rows, each asset is represented by the inclusion of a column for each possible (mutually exclusive and exhaustive) ownership category of that asset. In other words, each categorical asset ownership variable is reduced to a set of binary indicators. In this way, every household will indicate a " 1 ", in exactly one of each asset's set of columns or categories, and a " 0 "' in all other columns. Secondly, the profiles of the households relative to the categories of asset ownership are calculated. The row profiles of a matrix are the rows of that matrix, each divided by its row sum. Thirdly, MCA is applied to the original indicator matrix, and provides a set of category-weights from the first dimension or factorial axis of the analysis results. Fourthly, these MCA category-weights are applied to the profile matrix. A household's MCA composite indicator score is calculated by adding up all of that unit's weighted responses.

The Table 3, which also reports the weights for each index component, shows that those components that reflect higher standards of living contribute positively to the asset index, while components that reflect lower standards of living contribute negatively to the wealth index across countries. For example, owning a bicycle, owing a draft cattle or having a house with a good quality roofing material increases a household's asset index score in some countries; while not owning a bicycle, a radio, or living in a house with poor floor quality decreases a household's asset index score, that is, measured level of welfare.

\section{Results}

\subsection{Poverty Analysis Results}

The choice of poverty line is crucial for poverty analysis using FGT measures. There is no apparent non-arbitrary level at which to set it. The poverty lines set by [13] were, compared to their earlier study [13], set at relatively high levels, where the discrimination ability of asset indices was somewhat better.

In our non-monetary poverty framework the choice of the poverty line is somewhat less debatable for two reasons. Firstly, the definition of an absolute poverty line is not obvious since the welfare composite index used here does not include the nutritional dimension which is helpful in determining a minimal subsistence threshold. Secondly, there is a need to determine a set of welfare indicators deemed essential for every individual to achieve a minimum level of well-being. Based on this second reason, we chose one higher poverty line set at the $75^{\text {th }}$ percentile because Africa has substantially higher level of poverty than other world regions and the asset index does not discriminate well at very low levels. Table 4 presents the monetary-based poverty indicators of households estimated using the standard poverty line of USD 1.25 per equivalent adult adjusted with the local purchasing power parity (PPP) exchange rate, below which a household was classified as being poor and above which a household was classified as being non-poor, while Table 5 provides a summary of the monetary and non-monetary-based poverty indicators.

The poverty measures include the headcount index, the poverty gap, and the squared poverty gap. The headcount index is the percentage of the population living in households with income per capita below the poverty threshold. However, the headcount index ignores the amounts by which the income of the poor falls short of the poverty threshold. Hence the poverty gap index which gives the mean distance below the poverty line as a proportion of the poverty line is also computed, the squared poverty gap index which indicates the severity of poverty is computed by weighting the individual poverty gaps by the gaps themselves, so as to reflect inequality among the poor.

From the summary in Table 5, it is clear that communities in the study area deal with pervasive rural poverty: 
Table 1. Distribution of households by country, LGA and villages.

\begin{tabular}{|c|c|c|c|}
\hline Country & Locality/LGA/Sub-county & Number of villages & Number of household \\
\hline \multirow{10}{*}{ DRC } & Buzi & 20 & 198 \\
\hline & Bweremana & 6 & 49 \\
\hline & Jomba & 9 & 102 \\
\hline & Kamuronza & 10 & 97 \\
\hline & Kituva & 4 & 39 \\
\hline & Rubare & 4 & 38 \\
\hline & Rugari & 20 & 204 \\
\hline & Rumangabo & 6 & 69 \\
\hline & Total & 79 & 796 \\
\hline & Madarounfa & 5 & 50 \\
\hline \multirow{5}{*}{ NIGER } & Agui & 5 & 49 \\
\hline & Dakoro & 10 & 98 \\
\hline & Groumdji & 5 & 49 \\
\hline & Mayahi & 10 & 100 \\
\hline & Tessawa & 10 & 98 \\
\hline \multirow{6}{*}{ Nigeria Sahel } & Total & 45 & 444 \\
\hline & Maiadua & 10 & 100 \\
\hline & Rogo & 2 & 20 \\
\hline & Zango & 5 & 50 \\
\hline & Total1 & 17 & 170 \\
\hline & Bakori & 5 & 46 \\
\hline \multirow{11}{*}{ Nigeria NGS } & Dandume & 5 & 48 \\
\hline & Danja & 5 & 39 \\
\hline & Funtua & 5 & 45 \\
\hline & Giwa & 5 & 46 \\
\hline & Ikara & 5 & 50 \\
\hline & Kabau & 6 & 49 \\
\hline & Kudan & 5 & 44 \\
\hline & Makarfi & 3 & 26 \\
\hline & Sabon Gari & 5 & 43 \\
\hline & Soba & 5 & 50 \\
\hline & Zaria & 5 & 46 \\
\hline \multirow{11}{*}{ Nig Sudan } & Total 2 & 59 & 532 \\
\hline & Bunkure & 5 & 50 \\
\hline & Dan Musa & 10 & 100 \\
\hline & Dawakin Tofa & 10 & 100 \\
\hline & Ingawa & 10 & 100 \\
\hline & Karaye & 10 & 99 \\
\hline & Musawa & 5 & 50 \\
\hline & Safana & 5 & 50 \\
\hline & Shanono & 5 & 50 \\
\hline & Total 3 & 60 & 599 \\
\hline & Total Nigeria & 136 & 1,301 \\
\hline \multirow{8}{*}{ Rwanda } & Bigogwe & 20 & 176 \\
\hline & Gacaca & 10 & 99 \\
\hline & Gataraga & 10 & 99 \\
\hline & Mudende & 5 & 50 \\
\hline & Nyange & 20 & 186 \\
\hline & Remera & 6 & 97 \\
\hline & Rwerere & 5 & 48 \\
\hline & Total & 79 & 755 \\
\hline \multirow{9}{*}{ Uganda } & Bubare & 5 & 46 \\
\hline & Bufundi & 10 & 98 \\
\hline & Chahi & 10 & 103 \\
\hline & Hamurwa & 10 & 95 \\
\hline & Itojo & 10 & 88 \\
\hline & Kayonza & 5 & 44 \\
\hline & Nyakabande & 20 & 194 \\
\hline & Rubaya & 20 & 190 \\
\hline & Total & 90 & 858 \\
\hline Malawi & & - & 483 \\
\hline Mozambique & & - & 520 \\
\hline
\end{tabular}




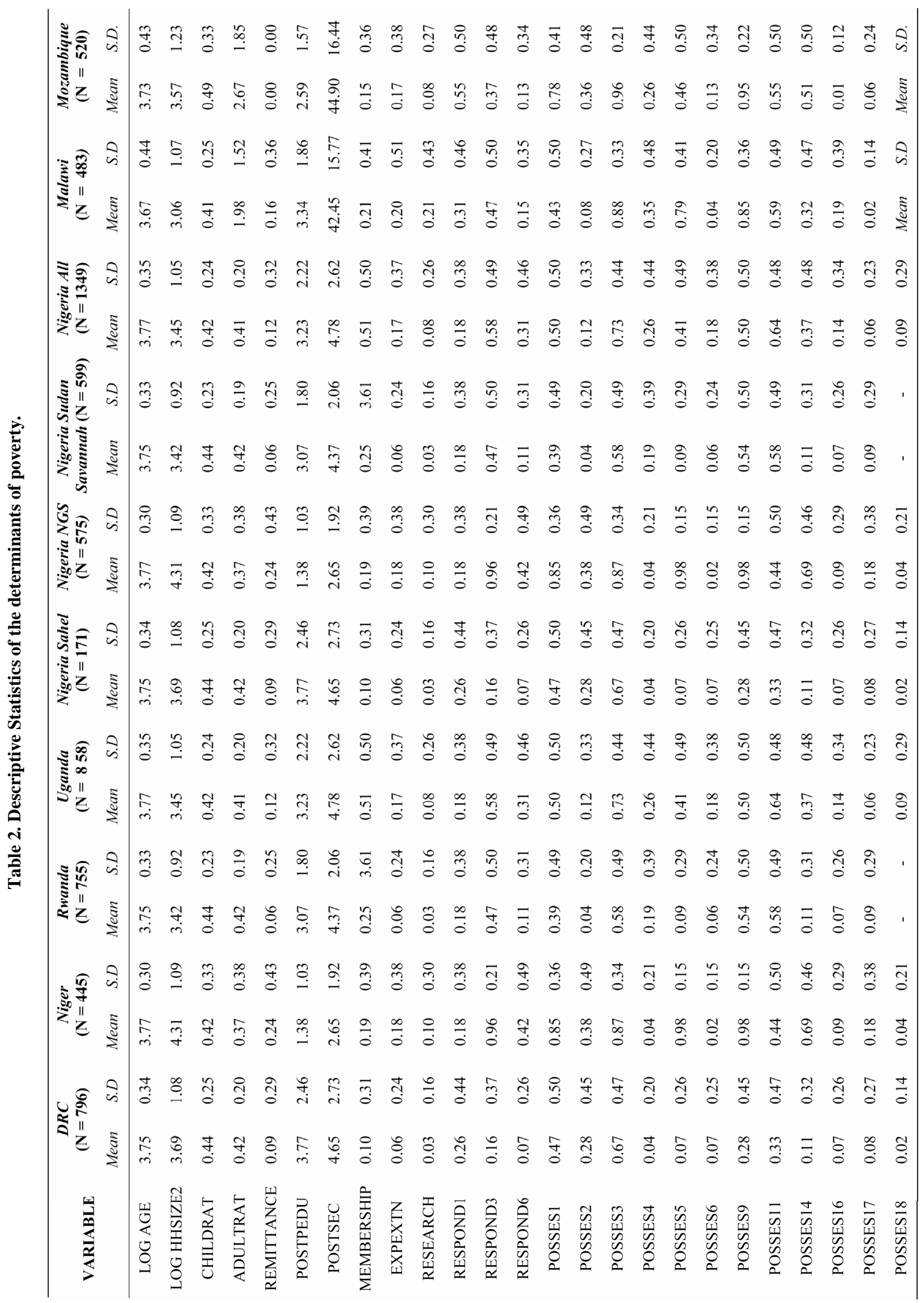


Table 3. Primary indicators.

\begin{tabular}{|c|c|c|c|c|c|c|c|c|}
\hline Variables & $\begin{array}{c}\text { Attribute } \\
(\%)\end{array}$ & $\begin{array}{c}\text { DRC } \\
(\mathrm{N}=370)\end{array}$ & $\begin{array}{c}\text { Malawi } \\
(\mathrm{N}=483)\end{array}$ & $\begin{array}{c}\text { Mozambique } \\
(\mathrm{N}=520)\end{array}$ & $\begin{array}{c}\text { Niger } \\
(\mathrm{N}=552)\end{array}$ & $\begin{array}{c}\text { Nigeria } \\
(\mathrm{N}=1131)\end{array}$ & $\begin{array}{c}\text { Rwanda } \\
(\mathrm{N}=599)\end{array}$ & $\begin{array}{c}\text { Uganda } \\
(\mathrm{N}=683)\end{array}$ \\
\hline Owns a bicycle & yes & 0.027 & 0.068 & 0.027 & 0.030 & 0.094 & -0.014 & -0.457 \\
\hline \multirow[t]{2}{*}{ Owns draft cattle } & yes & - & -0.008 & -0.067 & 0.624 & 0.139 & -0.014 & -0.436 \\
\hline & no & - & 1.939 & 0.003 & -0.016 & -0.255 & 8.5 & 0.001 \\
\hline \multirow[t]{2}{*}{ Owns draft donkeys } & yes & - & - & -0.002 & 0.860 & 0.060 & -0.014 & - \\
\hline & no & - & - & 0.265 & -0.002 & -0.472 & 8.5 & - \\
\hline \multirow[t]{2}{*}{ Owns a mobile phone } & yes & 0.025 & 0.061 & -0.246 & -0.537 & 0.179 & -0.016 & 0.019 \\
\hline & no & -0.548 & -0.605 & 0.001 & 0.007 & -0.215 & 0.001 & -0.001 \\
\hline Owns a motorcycle & no & -0.550 & -0.003 & -1.001 & 0.002 & -0.047 & 0.000 & 0.009 \\
\hline \multirow[t]{2}{*}{ Owns an oxcart } & yes & - & -0.02 & 0.006 & -0.010 & 0.074 & - & - \\
\hline & no & - & 1.53 & -1.461 & 1.124 & -0.519 & - & - \\
\hline \multirow[t]{2}{*}{ Owns an ox-plough } & yes & - & -0.009 & 0.016 & -0.019 & 0.164 & -0.014 & -0.000 \\
\hline & no & - & 1.40 & -0.896 & 0.635 & -0.179 & 8.5 & 0.091 \\
\hline \multirow[t]{2}{*}{ Owns a radio } & yes & 0.071 & 0.121 & 0.053 & -0.094 & 0.007 & 0.024 & 0.050 \\
\hline & no & -0.139 & -0.125 & -0.196 & 0.002 & -0.057 & -0.02 & -0.015 \\
\hline \multirow[t]{2}{*}{ Owns a sewing machine } & yes & 0.019 & 0.013 & 0.003 & -0.534 & 0.002 & -0.016 & 0.192 \\
\hline & no & -0.518 & -0.45 & -0.106 & 0.004 & -0.002 & 0.000 & -0.001 \\
\hline Owns a television & no & -0.760 & -0.681 & -1.552 & 0.002 & -0.034 & 0.000 & 0.009 \\
\hline \multirow[t]{2}{*}{ Quality of the roofing material } & Good quality & 0.142 & 0.109 & 0.283 & -0.06 & 0.091 & -0.021 & -0.004 \\
\hline & Other & -0.053 & -0.275 & -0.041 & 0.008 & -0.090 & 0.020 & 0.034 \\
\hline \multirow[t]{2}{*}{ Quality of the floor material } & Good quality & 0.038 & 0.037 & 0.342 & - & 0.053 & -0.022 & 0.045 \\
\hline & Other & -0.342 & -0.258 & -0.029 & - & -0.090 & 0.002 & -0.006 \\
\hline \multirow[t]{2}{*}{ Quality of the walls material } & Good quality & 0.032 & 0.101 & 0.132 & -0.005 & 0.100 & -0.015 & 0.098 \\
\hline & Other & -0.461 & -0.063 & -0.031 & 0.002 & -0.002 & 0.004 & -0.008 \\
\hline \multirow[t]{2}{*}{ Number of people per room } & Less than two & -0.005 & 0.077 & 0.061 & 0.047 & -0.021 & 0.005 & -0.006 \\
\hline & More than two & 0.004 & -0.034 & -0.019 & -0.028 & 0.033 & -0.020 & 0.016 \\
\hline \multicolumn{9}{|l|}{ Wealth index } \\
\hline Lowest value & & -0.01 & 0.00 & -0.19 & -1.34 & -0.02 & -0.08 & -1.28 \\
\hline $25^{\text {th }}$ Percentile & & 0.07 & 0.12 & 0.00 & 0.00 & 0.24 & -0.02 & -0.01 \\
\hline Median & & 0.13 & 0.21 & 0.03 & 0.00 & 0.40 & 0.00 & -0.01 \\
\hline Mean & & 0.13 & 0.24 & 0.12 & 0.01 & 0.41 & 0.00 & -0.03 \\
\hline $75^{\text {th }}$ Percentile & & 0.21 & 0.36 & 0.13 & 0.05 & 0.56 & 0.01 & 0.04 \\
\hline Highest value & & 0.34 & 0.71 & 0.89 & 0.48 & 1.053 & 0.03 & 0.34 \\
\hline
\end{tabular}


Table 4. Monetary-based poverty indicators by countries and communities.

\begin{tabular}{|c|c|c|c|c|}
\hline Country & Locality/LGA/Sub-county & Head count index & Poverty gap & Severity of poverty \\
\hline \multirow{10}{*}{ DRC } & Buzi & 98 & 91 & 85 \\
\hline & Bweremana & 96 & 86 & 82 \\
\hline & Jomba & 98 & 97 & 96 \\
\hline & Kamuronza & 98 & 97 & 94 \\
\hline & Kituva & 97 & 93 & 91 \\
\hline & Rubare & 98 & 90 & 83 \\
\hline & Rugari & 99 & 96 & 94 \\
\hline & Rumangabo & 98 & 93 & 90 \\
\hline & Total DRC & 98 & 95 & 91 \\
\hline & Madarounfa & 92 & 78 & 66 \\
\hline \multirow{5}{*}{ NIGER } & Agui & 90 & 71 & 57 \\
\hline & Dakoro & 90 & 69 & 49 \\
\hline & Groumdji & 93 & 76 & 61 \\
\hline & Mayahi & 92 & 73 & 56 \\
\hline & Tessawa & 91 & 72 & 63 \\
\hline \multirow{6}{*}{$\begin{array}{c}\text { Nigeria } \\
\text { Sahel }\end{array}$} & Total Niger & 91 & 75 & 56 \\
\hline & Maiadua & 92 & 81 & 75 \\
\hline & Rogo & 65 & 47 & 42 \\
\hline & Zango & 88 & 71 & 78 \\
\hline & Total Nigeria Sahel & 84 & 73 & 68 \\
\hline & Bakori & 62 & 44 & 35 \\
\hline \multirow{11}{*}{$\begin{array}{c}\text { Nigeria } \\
\text { NGS }\end{array}$} & Dandume & 62 & 40 & 31 \\
\hline & Danja & 76 & 49 & 39 \\
\hline & Funtua & 69 & 38 & 27 \\
\hline & Giwa & 57 & 42 & 35 \\
\hline & Ikara & 66 & 39 & 27 \\
\hline & Kabau & 70 & 51 & 42 \\
\hline & Kudan & 85 & 63 & 52 \\
\hline & Makarfi & 66 & 37 & 28 \\
\hline & Sabon Gari & 71 & 53 & 44 \\
\hline & Soba & 76 & 52 & 43 \\
\hline & Zaria & 83 & 61 & 48 \\
\hline \multirow{11}{*}{ Nig Sudan } & Total Nigeria NGS & 70 & 47 & 38 \\
\hline & Bunkure & 92 & 62 & 47 \\
\hline & Dan Musa & 94 & 76 & 66 \\
\hline & Dawakin Tofa & 80 & 59 & 49 \\
\hline & Ingawa & 88 & 61 & 49 \\
\hline & Karaye & 81 & 57 & 51 \\
\hline & Musawa & 70 & 49 & 39 \\
\hline & Safana & 90 & 59 & 51 \\
\hline & Shanono & 92 & 67 & 57 \\
\hline & Total Nigeria Sudan & 86 & 61 & 51 \\
\hline & Total Nigeria & 80 & 59 & 50 \\
\hline \multirow{8}{*}{ Rwanda } & Bigogwe & 96 & 84 & 76 \\
\hline & Gacaca & 98 & 87 & 79 \\
\hline & Gataraga & 98 & 89 & 82 \\
\hline & Mudende & 98 & 91 & 85 \\
\hline & Nyange & 96 & 77 & 66 \\
\hline & Remera & 98 & 86 & 77 \\
\hline & Rwerere & 98 & 92 & 86 \\
\hline & Total Rwanda & 98 & 84 & 76 \\
\hline \multirow{9}{*}{ Uganda } & Bubare & 97 & 85 & 76 \\
\hline & Bufundi & 98 & 91 & 85 \\
\hline & Chahi & 98 & 88 & 80 \\
\hline & Hamurwa & 98 & 88 & 76 \\
\hline & Itojo & 95 & 82 & 72 \\
\hline & Kayonza & 98 & 86 & 75 \\
\hline & Nyakabande & 98 & 86 & 78 \\
\hline & Rubaya & 98 & 89 & 82 \\
\hline & Total Uganda & 98 & 87 & 79 \\
\hline
\end{tabular}


Table 5. Monetary and non-monetary poverty index by country.

\begin{tabular}{|c|c|c|c|c|c|c|}
\hline \multirow{3}{*}{ Country } & \multicolumn{6}{|c|}{ Poverty indicators } \\
\hline & \multicolumn{2}{|c|}{ Head count index } & \multicolumn{2}{|c|}{ Poverty gap } & \multicolumn{2}{|c|}{ Severity of poverty } \\
\hline & Monetary & Non-monetary & Monetary & Non-monetary & Monetary & Non-monetary \\
\hline DRC & 98 & 81 & 95 & 39 & 91 & 28 \\
\hline Malawi & & 76 & & 39 & & 30 \\
\hline Mozambique & & 73 & & 62 & & 59 \\
\hline Niger & 91 & 77 & 75 & 69 & 56 & 52 \\
\hline Nigeria & 80 & 75 & 59 & 57 & 50 & 47 \\
\hline Rwanda & 98 & 83 & 84 & 73 & 76 & 67 \\
\hline Uganda & 98 & 84 & 87 & 65 & 79 & 54 \\
\hline
\end{tabular}

nearly $80-98 \%$ of the rural households in DRC, Niger, Nigeria, Rwanda and Uganda are below the poverty line. Rural poverty is also unevenly spread in these countries (as reflected by a poverty-gap ratio of $91 \%$ in DRC, $75 \%$ in Niger, $59 \%$ in Nigeria, $84 \%$ in Rwanda and $87 \%$ in Uganda) and severe as reflected by a squared poverty gap ratio of $85 \%$ in DRC, $56 \%$ in Niger, $50 \%$ in Nigeria, $76 \%$ in Rwanda and $79 \%$ in Uganda.

The spread, depth and severity of rural poverty differ among countries. In terms of all measures, Nigeria ranks as the country with the least rural poverty (a headcount ratio of $80 \%$, a poverty-gap measure of $59 \%$ and a squared poverty-gap measure of 50\%). At the other extreme are the Democratic Republic of Congo (DRC), Rwanda, Uganda and Niger Republic, which rank as countries with the highest poverty ( $98 \%$ and $91 \%$ of their rural households are living below a poverty line). All these countries have a rural poverty incidence in excess of $60 \%$.

Results from the non-monetary based approach, indicated in Table 5, seem to draw the same conclusions with small differences in the magnitude of the rural poverty index $(73 \%-84 \%)$.

\subsection{Determinants of Poverty}

In this section, we estimate the determinants of rural poverty by the logit Model in order to find out why some households are poor and others are not. The dependent variable is poverty incidence, which is 1 when the household is poor, and 0 if not. Table 6 gives the marginal effect estimates for the poverty determinants equation. The estimations have been made separately for each of the countries in order to check whether the factor considered have similar impact on poverty.

From Table 6 it can be clearly seen that in general, the factors strongly associated with poverty (household size, the proportion of children in the household and that of adults, household post secondary educational status, membership to a community group, access to agricultural extension agents, participation in community agricultural research demonstration activities, existence of a market within the village, existence of linkage between the village community and any trader or processor, existence of any agro-dealer shop within the village community, possession by the village of any school, social hall center, boreholes or wells, radio-reception channel, rural microfinance bank and, agricultural research site) are the same for most of the countries involved. However, the magnitude of the coefficients associated with these regressors varies across the countries. Moreover, the number of family members has positive and statistically significant estimates in many of these countries except in Malawi and Mozambique. The result confirms the common belief that larger number of family members is one of the most important causes of rural poverty in the study area. With very few exceptions, post-secondary education helps reduce poverty regardless of the magnitude of the coefficients. It is also clear from the comparison of its estimates in different estimations that education also matters much more to poverty defined by monetary than by non-monetary based measures.

A group of variables have been incorporated to capture the effects of community features on poverty. Undoubtedly, both the socioeconomic and geographical features of a community are important to the poverty status of the households that reside within the community. It has been found that in general, households that reside in villages where there is a market, linkage with any trader or processor, agro-dealer shop and those pos sessing any school, social hall center, boreholes or wells, radio-reception channel, rural microfinance bank and, agricultural research site, are less likely to fall into poverty.

Contact with agricultural extension agents and participation in community research demonstration activities positively improve the poverty status of households. In fact, regular contacts with agricultural extension agents and participation in community research demonstration 


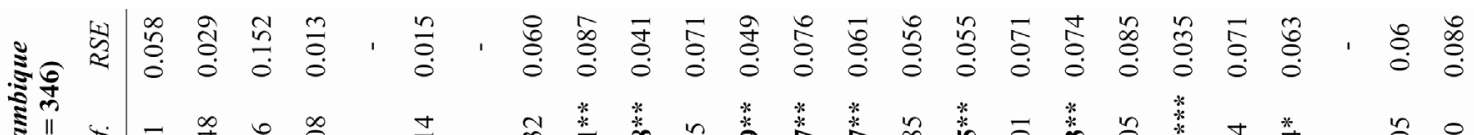

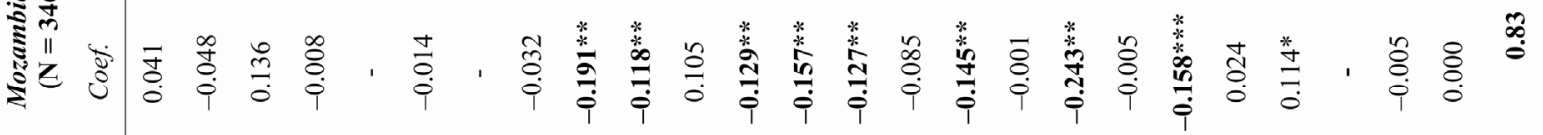

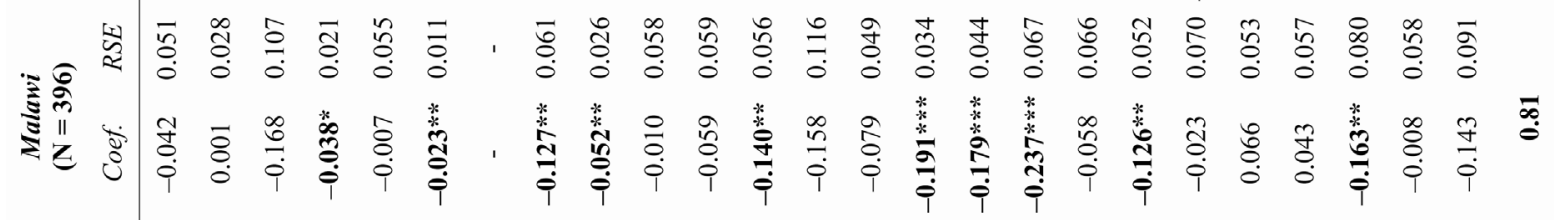

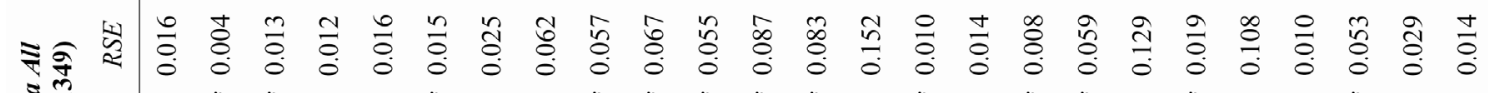

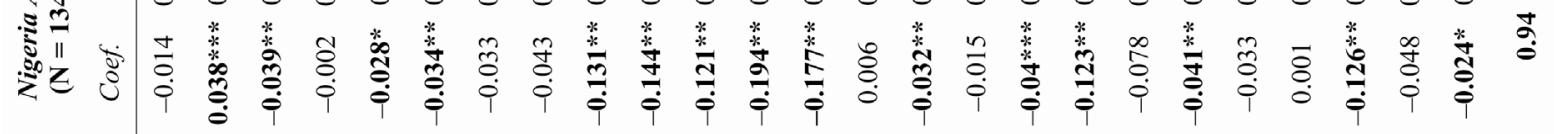

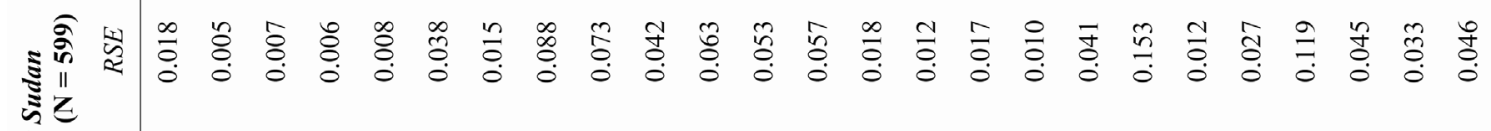

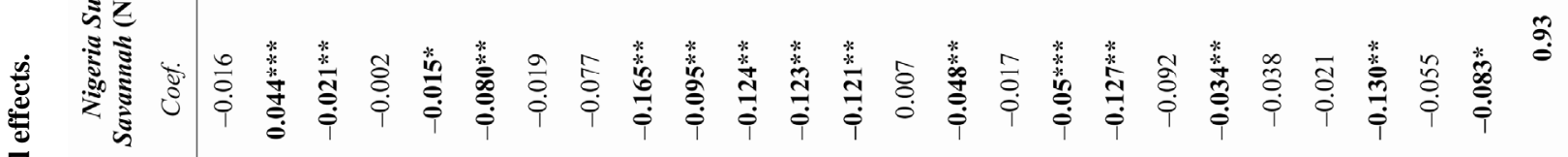

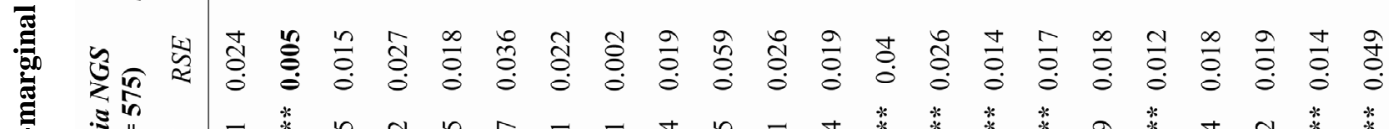

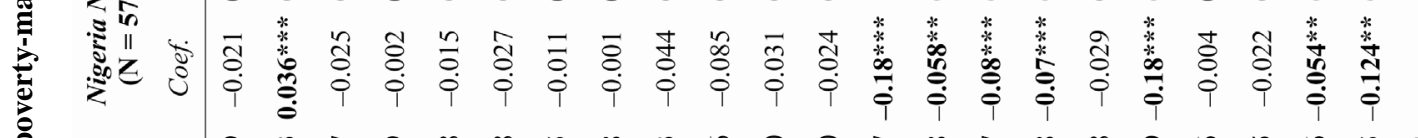

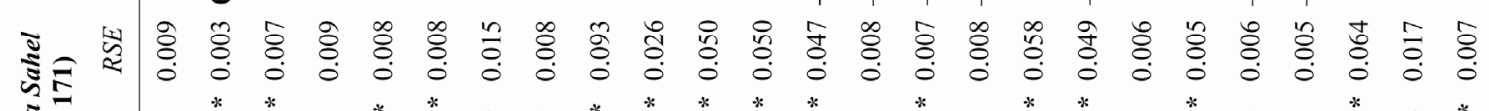

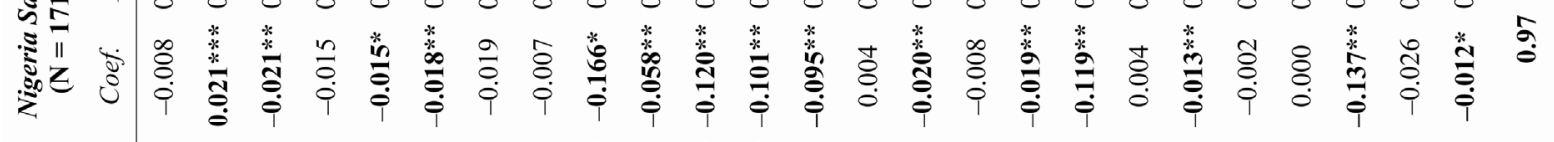

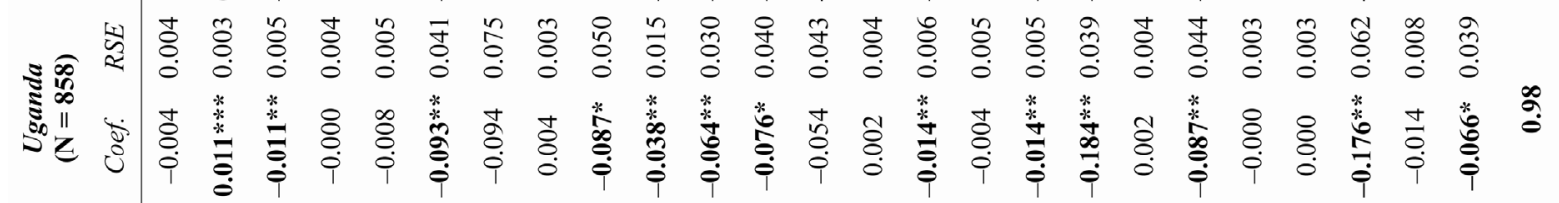

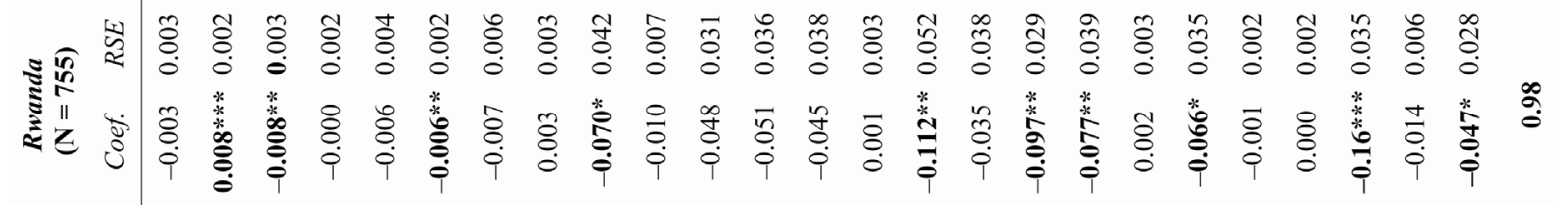

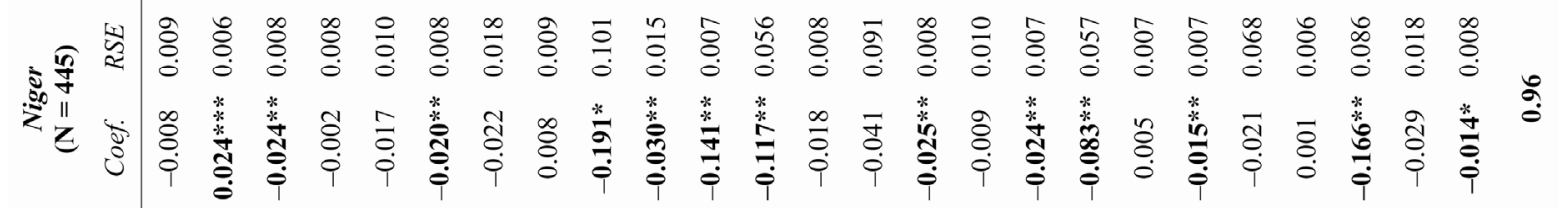

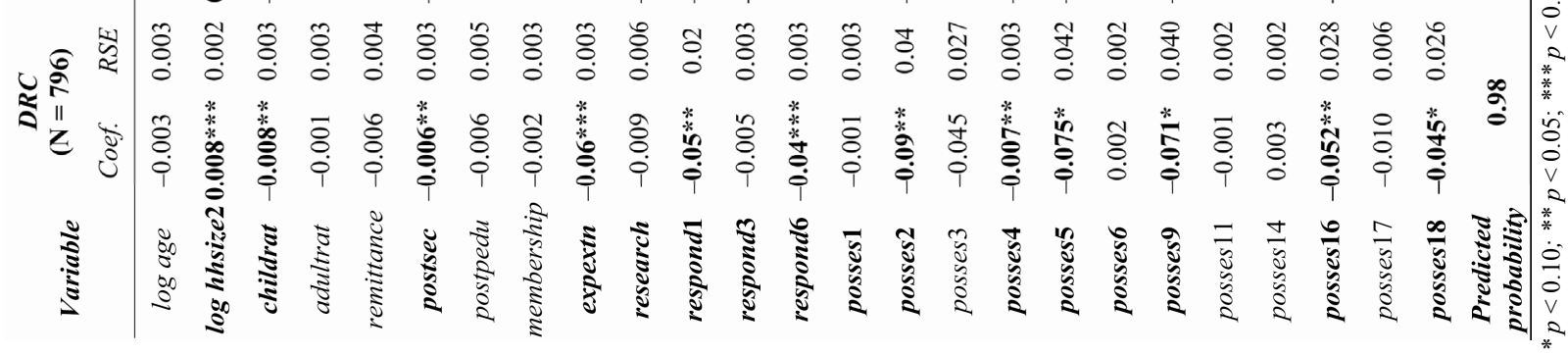


activities lead to the adoption of improved technologies. The role of agricultural technology change in reducing rural poverty and fostering overall economic development has been widely documented in the economic literature. Although quite complex, the relationship between the adoption of new technology and poverty reduction has been perceived to be positive [31-34]. The effects of new agricultural technology on poverty may be direct or indirect. The direct effects of new agricultural technology on poverty reduction are the productivity benefits enjoyed by the farmers who actually adopt the technology. These benefits usually manifest themselves in the form of higher farm incomes. The indirect effects are productivity-induced benefits passed on to others by the adopters of the technology. These may comprise lower food prices, higher nonfarm employment levels or increase in the consumption of food by all farmers [35].

Having estimated the poverty determinants, we can now generate simulations to predict reductions/increases in general poverty levels that result from changes in selected community/institutional characteristics. The purpose is to illustrate how changes in levels of the determinants will alter aggregate poverty levels. These changes are such as those that may result from the implementation of the Integrated Agricultural for Development (IAR4D) approach. Our simulations involve changing the variables at the community/local level. We choose to change variables that are significant and amenable to change with the correct implementation of IAR4D approach.

First, we consider the potential impact of linkage between the village/community and trader/processor, rural micro-finance institution and then, agro-dealers. In this situation we are trying to capture improvements in partnership/interaction among different actors throughout the product value chain as a means of improving accessibility of rural communities to output market and transport, credit and inputs (chemicals and fertilizer).

The results from Table 7 show that improving partnership/inter-action between the village/communities and traders/processors, micro-finance institution and agrodealers within the communities could potentially lower average location-level poverty rates by $11 \%$ in DRC, $30 \%$ in Malawi, 29\% in Mozambique and Niger Republic, $50 \%$ in Nigeria, $16 \%$ in Rwanda and 26\% in Uganda respectively (which would imply $88 ; 119 ; 100 ; 129 ; 675$; 121 and; 223 poor people escaping poverty in DRC, Malawi, Mozambique, Niger, Nigeria, Rwanda and, Uganda respectively). The poverty-effect for DRC and Rwanda is relatively small $(11 \%$ and $16 \%)$. Perhaps the disappointment aspect of this simulation is that the expected reduction in poverty is very small in these countries. This result holds true in terms of poverty reduction when we look at the sign of the coefficients. However, it should be noted that the small magnitude of the coefficients are results of change in a set a variables that cannot be the panacea for the poverty problems in these specific countries due to their difficult previous situation.

We also simulate the potential combined direct effect of improving interaction with extension services and research, the establishment of a market within the village together with the entire selected variables simulated in scenario 1 . In this situation we are trying to capture improvements in partnership/interaction among different actors throughout the products value-chain as a means of not only improving accessibility of rural communities to output market, transport, credit and inputs (chemicals and fertilizer), but also improving awareness and adoption of improved crop varieties, best-bet agricultural practices as well as inputs and outputs market information.

The results from Table 8 suggest that the poverty rate for DRC, Malawi, Mozambique, Niger, Nigeria, Rwanda and, Uganda could be lowered by $17 \%, 57 \%, 60 \%, 65 \%$, $89 \%, 16 \%$ and $45 \%$ respectively with investment/actions leading to access to input and output markets, awareness and adoption of improved crop varieties and best-bet practices, better access to rural credit and capacity building of community-based organizations.

\section{Conclusions and Recommendations}

Well-known scholars, politicians, foundations and academic groups have highlighted poverty in Africa as a priority development challenge and have dedicated considerable effort and resources toward its alleviation. Despite this widespread attention, confusion still exists over the language and evidence used to identify poverty in Africa and this is especially true for the Sub-Saharan Africa.

In this paper, we have sought to improve our general understanding of how (and which) institutional/community factors are related to poverty and how these factors vary across some selected countries in East, Southern and West Africa. In addition, we determine the extent to which the variation in poverty incidence can be explained by institutional/community factors, and how the results can be used to evaluate the potential impact on poverty levels of change in factors found to have a significant influence on poverty incidence. We found that:

- The communities in the study area deal with pervasive rural poverty: nearly $80 \%-98 \%$ of the rural households in DRC, Niger, Nigeria, Rwanda and Uganda are below the poverty line. Rural poverty is also unevenly spread in these countries (as reflected by a poverty-gap ratio of $91 \%$ in DRC, $75 \%$ in Niger, $59 \%$ in Nigeria, $84 \%$ in Rwanda and $87 \%$ in Uganda) 
Table 7. Predicting the effect of changes of some selected variables on poverty: first scenario.

\begin{tabular}{|c|c|c|c|c|c|c|c|c|c|c|}
\hline Selected variable & $\begin{array}{c}\text { DRC } \\
N=796\end{array}$ & $\begin{array}{l}\text { Malawi } \\
\mathrm{N}=396\end{array}$ & $\begin{array}{c}\text { Mozambique } \\
\mathrm{N}=346\end{array}$ & $\begin{array}{l}\text { Niger Republic } \\
\qquad N=445\end{array}$ & $\begin{array}{l}\text { Nigeria } \\
\text { Sahel } \\
\mathrm{N}=171\end{array}$ & $\begin{array}{l}\text { Nigeria } \\
\text { NGS }^{\mathrm{a}} \\
\mathrm{N}=575\end{array}$ & $\begin{array}{l}\text { Nigeria } \\
\text { Sudan } \\
\mathrm{N}=599\end{array}$ & $\begin{array}{c}\text { Nigeria } \\
\mathrm{N}=1349\end{array}$ & $\begin{array}{l}\text { Rwanda } \\
\mathrm{N}=755\end{array}$ & $\begin{array}{r}\text { Uganda } \\
\mathrm{N}=858\end{array}$ \\
\hline $\begin{array}{l}\text { Linkage between } \\
\text { trader/processor }\end{array}$ & $-5 \%$ & $-14 \%$ & $-13 \%$ & $-12 \%$ & $-10 \%$ & & $-12 \%$ & $-19 \%$ & & $-8 \%$ \\
\hline $\begin{array}{l}\text { Agro-dealer shop } \\
\text { within the village }\end{array}$ & $1 \%$ & & $-16 \%$ & & $-10 \%$ & $-18 \%$ & $-12 \%$ & $-18 \%$ & & \\
\hline $\begin{array}{l}\text { Possession of rural } \\
\text { micro-finance bank }\end{array}$ & $-5 \%$ & $-16 \%$ & & $-17 \%$ & $-14 \%$ & & $-13 \%$ & $-13 \%$ & $-16 \%$ & $-18 \%$ \\
\hline Total effect & $-11 \%$ & $-30 \%$ & $-29 \%$ & $-29 \%$ & $-34 \%$ & $-18 \%$ & $-37 \%$ & $-50 \%$ & $-16 \%$ & $-26 \%$ \\
\hline
\end{tabular}

${ }^{\mathrm{a}}$ Northern Guinea Savannah.

Table 8. Predicting the effect of changes of some selected variables on poverty: Second scenario.

\begin{tabular}{|c|c|c|c|c|c|c|c|c|c|c|}
\hline Selected variable & $\begin{array}{c}\text { DRC } \\
\mathrm{N}=796\end{array}$ & $\begin{array}{l}\text { Malawi } \\
\mathrm{N}=396\end{array}$ & $\begin{array}{l}\text { Mozambique } \\
\mathrm{N}=346\end{array}$ & $\begin{array}{l}\text { Niger Republic } \\
\qquad \mathrm{N}=445\end{array}$ & $\begin{array}{c}\text { Nigeria } \\
\text { Sahel } \\
\mathrm{N}=171\end{array}$ & $\begin{array}{l}\text { Nigeria } \\
\text { NGS }^{\mathrm{a}} \\
\mathrm{N}=575\end{array}$ & $\begin{array}{c}\text { Nigeria } \\
\text { Sudan } \\
\mathrm{N}=599\end{array}$ & $\begin{array}{c}\text { Nigeria } \\
\mathrm{N}=1349\end{array}$ & $\begin{array}{l}\text { Rwanda } \\
\mathrm{N}=755\end{array}$ & $\begin{array}{l}\text { Uganda } \\
\mathrm{N}=858\end{array}$ \\
\hline $\begin{array}{l}\text { Linkage between } \\
\text { trader/processor }\end{array}$ & $-5 \%$ & $-14 \%$ & $-13 \%$ & $-12 \%$ & $-10 \%$ & & $-12 \%$ & $-19 \%$ & & $-8 \%$ \\
\hline $\begin{array}{l}\text { Agro-dealer shop } \\
\text { within the village }\end{array}$ & $1 \%$ & $16 \%$ & $-16 \%$ & & $-10 \%$ & $-18 \%$ & $-12 \%$ & $-18 \%$ & & \\
\hline $\begin{array}{l}\text { Possession of rural } \\
\text { micro-finance bank }\end{array}$ & $-5 \%$ & $-16 \%$ & & $-17 \%$ & $-14 \%$ & & $-13 \%$ & $-13 \%$ & $-16 \%$ & $-18 \%$ \\
\hline $\begin{array}{c}\text { Contact with } \\
\text { extension agent }\end{array}$ & $-6 \%$ & $-5 \%$ & $-19 \%$ & $-19 \%$ & $-17 \%$ & & $-17 \%$ & $-13 \%$ & $-7 \%$ & $-9 \%$ \\
\hline $\begin{array}{c}\text { Market within the } \\
\text { village }\end{array}$ & & $-6 \%$ & & $-14 \%$ & $-12 \%$ & & $-12 \%$ & $-12 \%$ & & $-6 \%$ \\
\hline $\begin{array}{l}\text { Participation to } \\
\text { community } \\
\text { research action }\end{array}$ & & & $12 \%$ & $-3 \%$ & $-6 \%$ & & $-10 \%$ & $-14 \%$ & & $-4 \%$ \\
\hline Total effect & $-17 \%$ & $-57 \%$ & $-60 \%$ & $-65 \%$ & $-69 \%$ & $-18 \%$ & $-76 \%$ & $-89 \%$ & $-16 \%$ & $-45 \%$ \\
\hline
\end{tabular}

and severe as reflected by a squared poverty gap ratio of $85 \%$ in DRC, $56 \%$ in Niger, $50 \%$ in Nigeria, $76 \%$ in Rwanda and 79\% in Uganda;

- The results of the bivariate logit model demonstrate the statistical significance of certain institutional /community variables. At the country level, the set of important variables is diverse and includes household specific characteristics, access to infrastructure (institutional dummy variables), and village resources endowment (community-based variables). This suggests the presence of a poverty-institutional/community relationship and hence the impact of institutional/community factors on the welfare of the poor and on poverty reduction efforts.

- However, the strength of the institutional/community variables shows that countries in the Challenge programme are not homogenous.

- Our simulation results suggest that: firstly, improving partnership/interaction between the village/community and traders/processors, micro-finance institution and agro-dealers within the communities could po- tentially lower average location-level poverty rates by $11 \%$ in DRC, 30\% in Malawi, 29\% in Mozambique and Niger Republic, 50\% in Nigeria, $16 \%$ in Rwanda and $26 \%$ in Uganda respectively (which would imply $88 ; 119 ; 100 ; 129 ; 675 ; 121$ and; 223 poor people escaping poverty in DRC, Malawi, Mozambique, Niger, Nigeria, Rwanda and, Uganda respectively). Secondly, the poverty rate for DRC, Malawi, Mozambique, Niger, Nigeria, Rwanda and Uganda could be lowered by $17 \%, 57 \%, 60 \%, 65 \%, 89 \%, 16 \%$ and $45 \%$, respectively with investment/actions leading to access to input and output markets, awareness and adoption of improved crop varieties and best-bet practices, better access to rural credit and capacity building of community-based organizations. These results indicate that these variables can have significant effects in terms of long-term reduction in poverty.

Finally, it should be noted that although this approach has helped explain the determinants of poverty, there is a need to refine and extend this analysis, including more 
inclusive poverty indicators (food-consumption-based indicators) as well as incorporating information from other data sources.

Implication for IAR4D's innovation platforms (IPS)

The Sub-Saharan Africa challenge programme set forth a new strategy for improving agricultural innovation outcomes through the integrated agricultural research for development operational approach (IAR4D). This approach aims to demonstrate the effectiveness of innovation systems in supporting the development and adoption of market driven crop/livestock productivity-enhancing technology options. An important dimension of the livelihood improvement expected from the IAR4D approach is food security, income for rural households and then, poverty alleviation.

The findings derived from this paper suggest that more than Fourth-fifths of households in the study area need to escape from poverty. To ensure this significant result, the innovation platforms established within the framework of the challenge programme need to:

- Develop and facilitate the sustainability of a system that encourages regular interactions and information-sharing among stakeholders (e.g., farmers' associations, entrepreneurs, NGOs, CBOs, micro-finance institution, development-oriented organizations, ministries, research and extension agencies);

- Promote and facilitate awareness and adoption of productivity-enhancing agricultural innovations that can contribute to raising incomes of rural households, poverty alleviation, and food security.

- Use current and new tools to understand more thoroughly the nature of existing institutions in action villages and their roles in social and economic development. Doing so should help ensure that taskforce IPs avoid weakening existing positive social capital, and identify areas where social capital needs to be strengthened.

\section{Reference}

[1] J. D. Sachs, "The End of Poverty," Penguin, New York, 2005.

[2] Chronic Poverty Research Centre, "The Chronic Poverty Report, 2004-05," University of Manchester, Manchester, 2006.

[3] R.W. Kates and P. Dasgupta, "African Poverty: A Grand Challenge for Sustainability Science," Proceedings of the National Academy of Sciences, Vol. 104, No. 43, 2007, pp. 16747-16750. doi:10.1073/pnas.0708566104

[4] P. D. Little, J. Mcpeak, C. B. Barret and P. Kristjanson, "Challenging Orthodoxies: Understanding Poverty in Pastoral Areas of East Africa," Development and Change, Vol. 39, No. 4, 2006, pp. 587-611. doi:10.1111/j.1467-7660.2008.00497.x
[5] World Bank, "Country Reports on Health, Nutrition, Population and Poverty," ****. http://www.worldbank.org/poverty/health/data/intro.htm

[6] A. Geda, S. K. Mwangi, D. J. Niek and G. Mwabu, "Determinants of Poverty in Kenya: A Household Level Analysis," Department of Economics Working Papers, University of Connecticut, 2005.

[7] P. O. Okwi, G. Ndenge, G. Kristjansonx, M. Arunga, A. Notenbaert, A. Amolo, N. Henninger, B. Todd, P. Kariuki and J. Owuol, "Spatial Determinants of Poverty in Rural Kenya," Proceedings of the National Academic of Sciences, Vol. 104, No. 43, 2007, pp. 16769-16774. doi:10.1073/pnas.0611107104

[8] F. N. Okurut, J. J. A. O. Odwee and A. Adebwa, "Determinants of Regional Poverty in Uganda," AERC Research Paper 122, African Economic Research Consortium, Narobi, 2002.

[9] R. Chambers, "Rural Development: Putting the Last First," Prentice Hall, Bergen, 1983.

[10] H. Colombe and A. Mckay, "Modeling Determinants of Poverty in Mauritania," World Development, Vol. 24, No. 6, 1996, pp. 1015-1031. doi:10.1016/0305-750X(96)00017-4

[11] S. Dercon, "Poverty Measurement," In: D. A. Clark, eds., The Elgar Companion to Development Studies, Edward Elgar, Cheltenham, 2005.

[12] D. Filmer and L. Pritchett, "Estimating Wealth Effects without Expenditure Data-or Tears: An application to Educational Enrollments in States of India," World Bank Policy Research Working Paper No. 1994, Washington, 1998.

[13] D. E. Sahn and D. C. Stifel, "Poverty Comparisons over Time and across Countries in Africa," World Development, Vol. 28, No. 12, 2000, pp. 2123-2155. doi:10.1016/S0305-750X(00)00075-9

[14] J. Y. Ducclos and A. Araar, "Poverty and Equity, Measurement, Policy and Estimation with DAD," University of Laval, Quebec, 2005.

[15] M.Ayadi, E. L.AbdelRahmen and N. Chtioui, "Poverty in Tunisia: A Non-Monetary Approach," PMMA Working Paper 2007-05, Poverty and Economic Policy Research Network, 2008.

[16] J. Galdo, M. Jaramillo and V. Montalva, "Household Wealth and Heterogeneous Impacts of a Market-Based Training Program: The Case of PROJOVEN in Peru," PMMA Working Paper 2008-02, Poverty and Economic Policy Research Network, 2008.

[17] F. Booysen, R. Burger, G. du Rand, M. von Maltitz and S.van der Berg, "Trends in Poverty and Inequality in Seven African Countries," PMMA Working Paper 2007-06, Poverty and Economic Policy Research Network, 2007.

[18] M. Ayadi, M.,Salah and M. P. Victoria-Feser, "Putting Robust Statistical Methods into Practice: Poverty Analysis in Tunisia," Swiss Journal of Economics and Statistics, Vol. 137, No. 3, 2001, pp. 463-482.

[19] L. M.Asselin, "Multidimentional Poverty: Composite 
Indicator of Multidimentional Poverty," Institut de Mathematique Gauss: Levis, Quebec, 2002.

[20] J. E. Foster, J. Greer and E. Thorbecke, "A Class of Decomposable Poverty Measures," Econometrica, Vol. 52, No. 3, 1984, pp. 761-776. doi:10.2307/1913475

[21] G. S. Maddala, "Limited Dependent and Qualitative Variables in Econometrics," Cambridge University Press, 1983.

[22] T. Amemiya, "Qualitative Response Models: A Survey," Journal of Economic Literature, Vol. 19, No. 4, 1981, pp. 1483-1536.

[23] X. Wang, S. Yao, J. Liu, X. Xin, X. Liu and W. Ren, "Measuring Rural Poverty in China: A Case Study Approach," PMMA Working Paper 2007-27, Poverty and Economic Policy Research Network, 2007.

[24] F. Sonja and W. Lindsay, "Determinants of Poverty in Sierra Leone," ESAU Working Paper 19, Oversea Development Institute, London, 2007.

[25] P. Lanjouw and M. Ravallion, "Poverty and Household size," The Economic Journal, Vol. 105, No. 433, 1995, pp. 1415-1434. doi:10.2307/2235108

[26] S. Mukherjee and B. Todd, "Determinants of Poverty in Malawi," World Development, Vol. 31, No. 2, 2003, pp. 339-358. doi:10.1016/S0305-750X(02)00191-2

[27] K. Simler, S. Mukherjee, G. Dava and G. Datt, "Rebuilding after War: Micro-Level Determinants of Poverty Reduction in Mozambique," IFPRI Working paper Series 132, Washington, 2004.

[28] P. Glewwe, "Investing Determinants of Household Welfare in Cote d'Ivoire," Journal of Development Economics, Vol. 35, No. 2, 1991, pp. 307-337.
doi:10.1016/0304-3878(91)90053-X

[29] T. Bruck, "Determinants of Rural Poverty in Post-War Mozambique: Evidence from a Household Survey and Implications for Government and Donor Policy," Queen Elisabeth House Working Paper Series No. 67, Oxford University, Oxford, 2001.

[30] C. Grootaert, O. Gi-Taik and A. Swamy, "Social Capital, Household Welfare and Poverty in Burkina Faso," Journal of African Economies, Vol. 86, No. 2, 2002, pp. 15-19.

[31] H. P. Binswanger and J. von Braun, "Technological Changes and Commercialization in Agriculture: The Effect on the Poor," World Bank research Observer, Vol. 6, No. 1, 1991, pp. 57-80. doi:10.1093/wbro/6.1.57

[32] M. R. Bellon, M. Adato, J. Bercerril and D. Mindek, "Poor Farmers' Perceived Benefits from Different Types of Maize Germplasm: The Case of Creolization in Low Land Tropical Mexico," World Development, Vol. 34, No. 1, 2006, pp. 113-129. doi:10.1016/j.worlddev.2005.05.012

[33] K. Yoko, O. Keijiro and D. Sserunkuuma, "Assessing the Impact of NERICA on Income and Poverty in Central and Western Uganda," Agricultural Economics, Vol. 38, No. 3, 2008, pp. 327-337. doi:10.1111/j.1574-0862.2008.00303.x

[34] J. Bercerril and A. Abdulai, "The Impact of Improved Maize Varieties on Poverty in Mexico: A Propensity Score-Matching Approach," World Development, Vol. 38, No. 7, 2010, pp. 1012-1023.

[35] A. de Janvry and E. Sadouley, "World Poverty and the Role of Agricultural Technology: Direct and Indirect Effect," Journal of Development Studies, Vol. 38, No. 4, 2001, pp. 1-26. doi:10.1080/00220380412331322401 